\title{
Effect of Surface Microstructures on Hydrophobicity and Barrier Property of Anticorrosive Coatings Prepared by Soft Lithography
}

\author{
Dawei Zhang, Haiyang Li, Xiaoli Chen, Hongchang Qian, and Xiaogang Li \\ Institute for Advanced Materials \& Technology, University of Science \& Technology Beijing, Beijing 100083, China \\ Correspondence should be addressed to Dawei Zhang; dzhang@ustb.edu.cn
}

Received 21 October 2014; Accepted 9 December 2014; Published 22 December 2014

Academic Editor: Vladimir Tsukruk

Copyright (C) 2014 Dawei Zhang et al. This is an open access article distributed under the Creative Commons Attribution License, which permits unrestricted use, distribution, and reproduction in any medium, provided the original work is properly cited.

\begin{abstract}
Enhancing the hydrophobicity of organic coatings retards their interaction with water and often leads to better protectiveness over metal corrosion. In this study, a soft lithography method was used to prepare epoxy coatings which showed surface microstructures in high replication to sandpapers. The effect of microstructures on coating's hydrophobicity and barrier property was investigated. Compared to flat coatings, the microstructured coatings showed much higher water contact angles, which further increased with finer sandpapers. Determined by electrochemical impedance spectroscopy (EIS), the flat coating exhibited a higher anticorrosive performance than the microstructured coatings. With the use of finer sandpaper, the groove size of the corresponding microstructured coating was reduced. And a lower anticorrosive performance was observed since more defects might be formed in a given area of coating during the imprinting process. As the groove size of the coatings was further decreased to $5.7 \mu \mathrm{m}$, the microstructures became too small for water to easily penetrate through. Therefore, trapped air acted as an additional barrier and contributed to an increased anticorrosive performance compared to other microstructured coatings.
\end{abstract}

\section{Introduction}

Corrosion poses significant threats to the reliability of engineering materials and structures and costs an economic loss of $\sim 3 \%$ GDP. Among all corrosion mitigation methods, considerable research interests have been given to barrier coatings, which physically isolate metallic substrates from corrosive species such as water, oxygen, and chloride ions [1]. However, with long-term exposure to corrosive environment, the absorbed water on the coating surface will inevitably penetrate to the coating/substrate interface, eventually leading to the loss of adhesion and protectiveness thereof [2-4].

Surface hydrophobization reduces water wetting and thus the interaction between water and coating. It has shown proven effectiveness in prolonging the service life of anticorrosive coatings [5-7]. In general, the surface hydrophobicity of anticorrosive coatings can be increased by incorporating hydrophobic components or surface roughening to create micro/nanostructures [8]. For example, branched aminopolydimethylsiloxane (PDMS) was blended and cured with epoxies [2]. The obtained interpenetrated polymer network (IPN) coatings exhibited lower water diffusion coefficients and significant improvement in anticorrosive properties against hygrothermal cycling. Besides siloxanes, fluorine-containing segments were also used to enhance coatings' hydrophobicity and barrier properties $[9,10]$.

Compared to flat surfaces which rarely show water contact angles $(\theta)$ above $120^{\circ}$, rough surfaces can achieve higher hydrophobicity and even a superhydrophobic state with $\theta>150^{\circ}$. On these surfaces, the air trapped in the micro/ nanostructures forms an additional barrier against water penetration [11]. In addition, these micro/nanostructures can produce an excellent self-cleaning effect on the superhydrophobic surface, where water droplets and dissolved corrosive species can easily roll off $[12,13]$. To date, such surfaces are mostly prepared by etching or hydrothermal conversion to generate micro/nanoscale roughness, followed by grafting hydrophobic chains [14-16]. However, the role of surface microstructures on the barrier properties of organic coatings has been rarely addressed. 
Soft lithography is a cost-effective micro/nanofabrication technique, which can precisely replicate a template to produce micro/nanostructures [17]. Chang et al. casted and cured PDMS onto a superhydrophobic Xanthosoma sagittifolium leaf and transferred the micropapillary structures on an epoxy-based graphene nanocomposite coating [18]. Compared to flat coating, the microstructured coating exhibits improved anticorrosive performance due to the inclusion of air in the microstructures.

Herein, commercially available sandpapers were used as templates to prepare solvent-free epoxy coatings with microstructured surface. By choosing the grit size of the sandpapers, the groove size of the microstructured coating was tailored. The hydrophobicity of the obtained coatings was compared via contact angle analysis and the effect of microstructures on barrier property of the coatings was investigated by electrochemical measurements.

\section{Materials and Methods}

2.1. Materials. Silicon Carbide (SiC) Sandpapers (P240, P400, P600, P1000, and P2000) were supplied by 3M. PDMS prepolymer and hardener (Sylgard 184) were purchased from Dow Corning. Bisphenol A diglycidyl ether (BADGE) and the hardener Jeffamine D230 were purchased from Sigma Aldrich. All reagents and solvents are used as received without further purification.

2.2. Preparation of PDMS Template. Sylgard 184 and its hardener $(10: 1, \mathrm{w} / \mathrm{w})$ were mechanically mixed at room temperature for $15 \mathrm{~min}$. The obtained precursor solution was poured onto sandpapers fixed in a $20 \times 20 \mathrm{~cm}$ mold. Subsequently, it was degassed in a vacuum oven to eliminate the air trapped in the microstructures of sandpapers to ensure fidelity of the replication. After curing at $60^{\circ} \mathrm{C}$ for $12 \mathrm{~h}$, the PDMS template was peeled off from the sandpaper.

2.3. Preparation of Epoxy Coatings. The Q235 steel substrate was polished with 240-grit sandpaper and cleaned with acetone in an ultrasonic bath before coating. BAGDE and Jeffamine D230 (3:1, w/w) were mechanically stirred at $40^{\circ} \mathrm{C}$ to obtain a clear mixture and then spread on the steel substrate. The PDMS template was subsequently pressed against the coating, followed by curing at $80^{\circ} \mathrm{C}$ for $2 \mathrm{~h}$ and $125^{\circ} \mathrm{C}$ for $3 \mathrm{~h}$. After peeling off the PDMS template, the microstructured epoxy coating was obtained, with a thickness of $\sim 60 \mu \mathrm{m}$.

2.4. Surface Morphology and Contact Angle Analysis. The microstructures on the sandpapers and the corresponding epoxy coatings were observed using scanning electron microscopy (SEM, FEI Quanta 250). To characterize the surface roughness of the coatings, arithmetic average of the roughness profile $\left(R_{a}\right)$ was determined on three different locations of each specimen by stylus profilometry (Shidai TA620). The groove size was determined using ImageJ software (http://rsb.info.nih.gov/ij/) by taking the average of 50 measurements of the distance between adjacent protrusions on the microstructured coatings. For contact angle analysis,

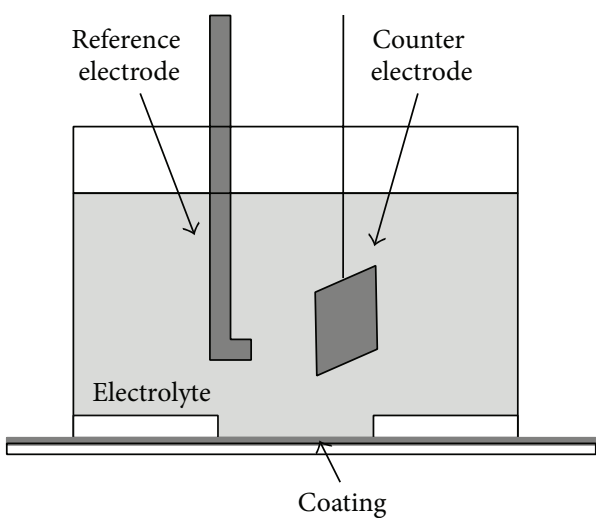

SCHEME 1: Experimental setup of the three-electrode system for EIS study.

a sessile water droplet of $5 \mu \mathrm{L}$ was placed onto the coating surface and the contact angle was immediately measured using Dataphysics OCA20 goniometer. The results reported are an average of five measurements taken on different areas of the specimen.

2.5. Electrochemical Impedance Spectroscopy (EIS). EIS measurements were performed at room temperature in $3.5 \mathrm{wt} \%$ $\mathrm{NaCl}$ solution with a PARSTAT 2273 electrochemical station, in the frequency range of $10^{5} \mathrm{~Hz}$ to $10^{-2} \mathrm{~Hz}$ at open circuit potential, with a $20 \mathrm{mV}$ AC perturbation. A three-electrode system was used, consisting of a saturated calomel electrode (SCE) as reference electrode, a platinum electrode as counter electrode, and the coated specimen as the working electrode (Scheme 1). Before impedance measurements, the working electrode was submersed in the test electrolyte for $30 \mathrm{~min}$ for stabilization. All measurements were repeated at least three times to ensure reproducibility.

\section{Results and Discussion}

3.1. Template-Assisted Fabrication. Soft lithography employs elastomeric templates, most notably made of PDMS, to construct micro/nanostructured surfaces with tailorable hydrophobicity and desirable functionalities [17]. However, to the best of our knowledge, only a few studies have applied soft lithography to prepare micro/nanostructured coating for anticorrosion purposes [18]. In this study, solvent-free epoxy anticorrosive coatings were prepared via a soft lithography method to obtain surface microstructures similar to sandpapers (Scheme 2). The PDMS templates made by Sylgard 184 are excellent elastomers with linear elastic region up to strain values of $\sim 40 \%$ [19]. Due to the low surface energy, they also show minimal adhesiveness to both the sandpapers and the cured epoxy coatings. Thus, they can be easily peeled off and repeatedly used without noticeable damage to their surface microstructures. Figure 1 shows SEM images of sandpapers with various grit sizes and their corresponding epoxy coatings. The microstructures of the epoxy coatings are in very close resemblance to those of the sandpapers. As the grit size of the sandpaper decreases from P240 to P2000, 


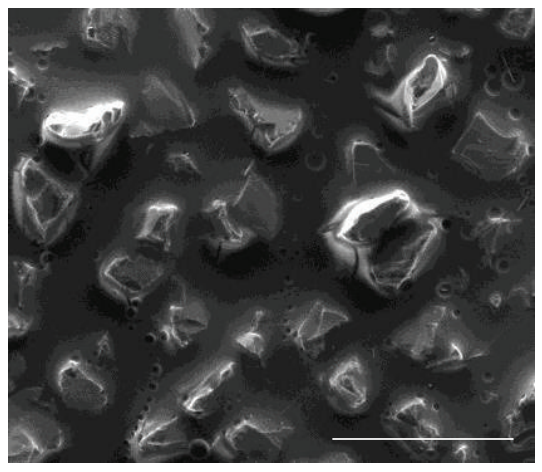

(a)

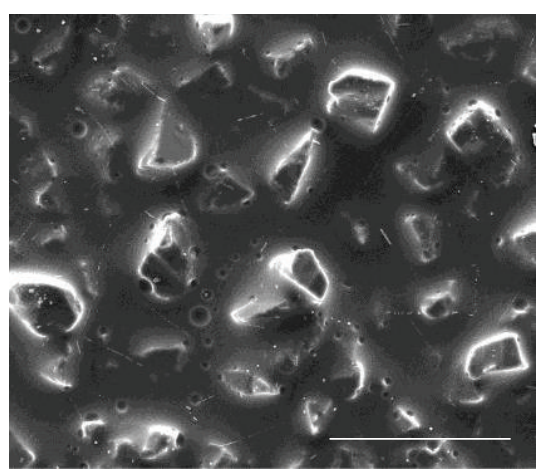

(d)

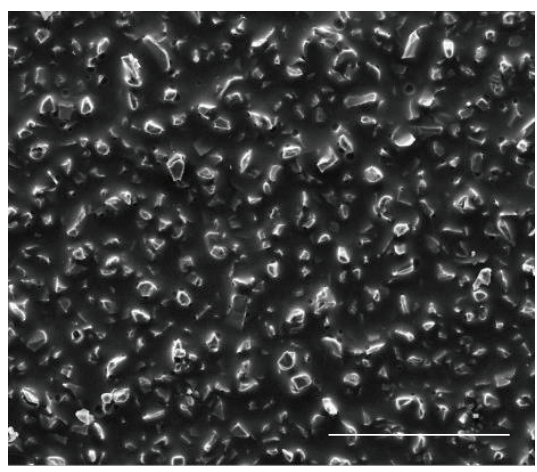

(g)

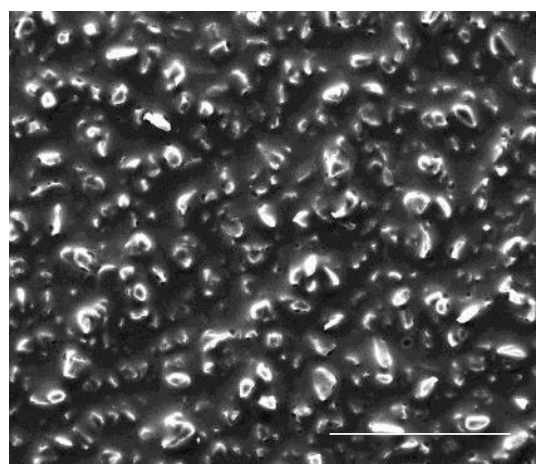

(j)

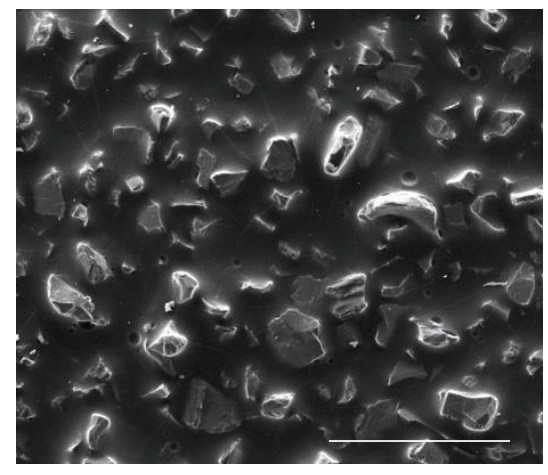

(b)

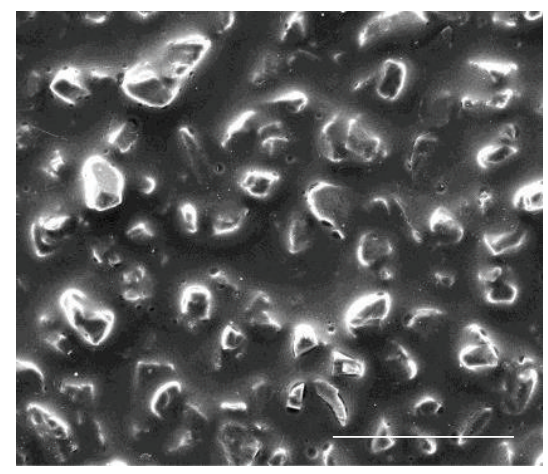

(e)

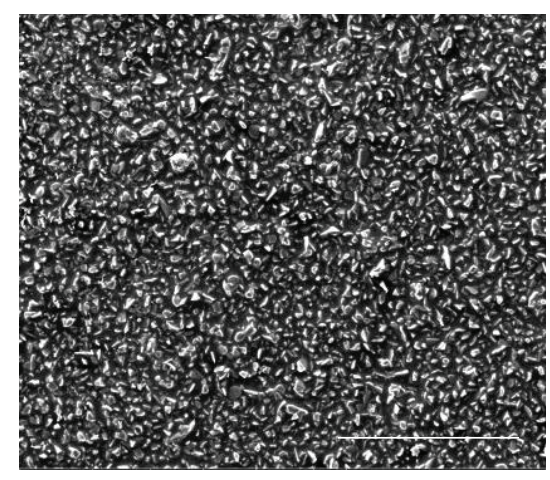

(h)

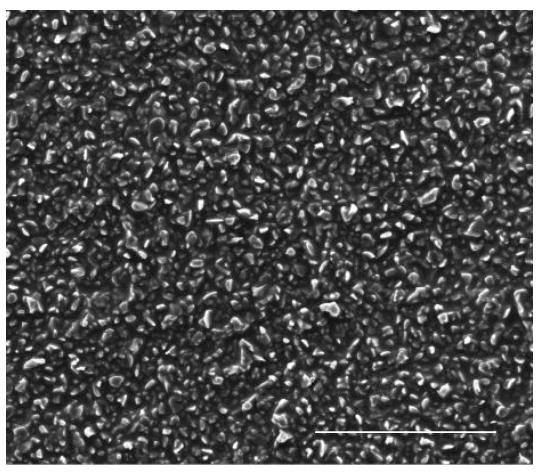

(k)

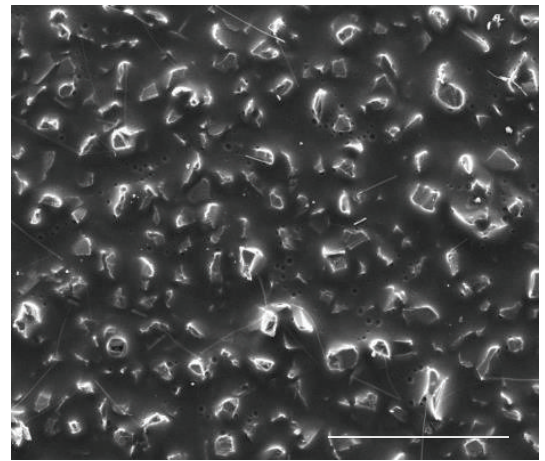

(c)

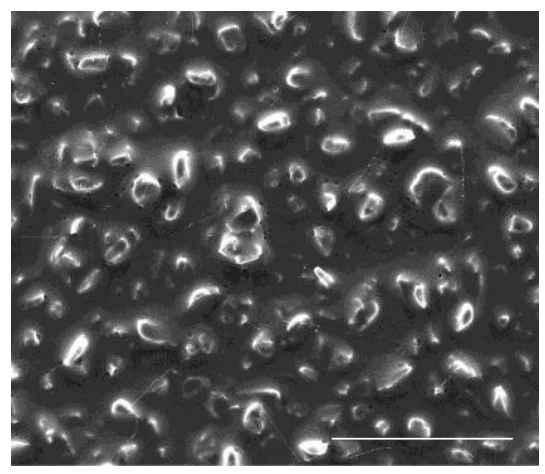

(f)

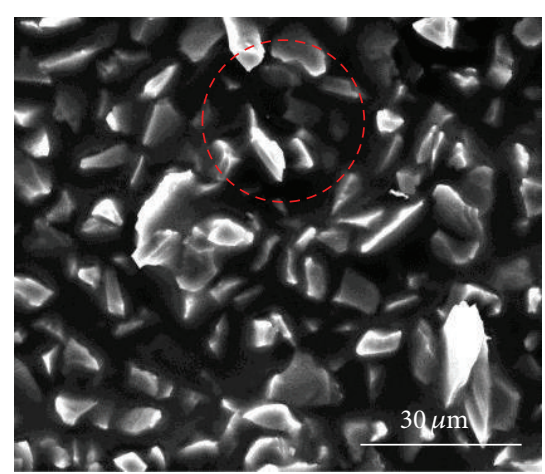

(i)

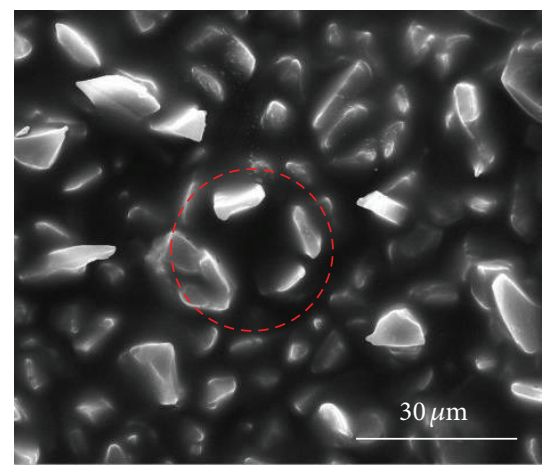

(1)

Figure 1: SEM images of sandpapers ((a) P240; (b) P400; (c) P600; (g) P1000; (h-i) P2000) and coatings ((d) P240; (e) P400; (f) P600; (j) P1000; (k-1) P2000). Scale bars are $200 \mu \mathrm{m}$ unless otherwise noted. 


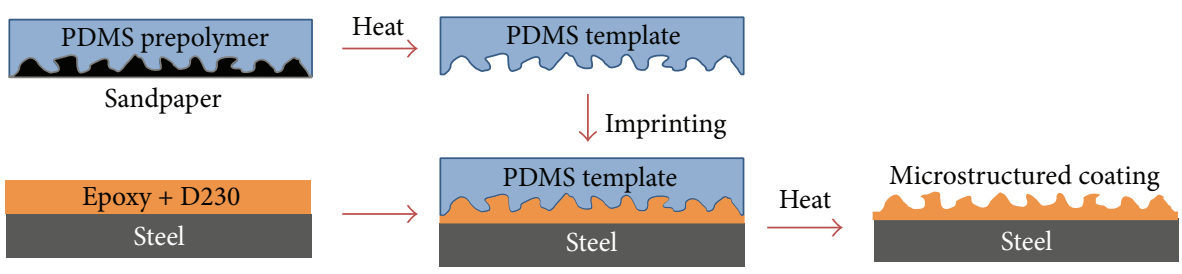

SCHEME 2: Soft lithography fabrication of sandpaper-like microstructured epoxy coatings.

TABLE 1: Surface roughness and groove sizes of the microstructured coatings.

\begin{tabular}{lccccc}
\hline Coating & P240 & P400 & P600 & P1000 & P2000 \\
\hline$R_{a}(\mu \mathrm{m})$ & $9.5 \pm 0.4$ & $7.5 \pm 0.3$ & $6.3 \pm 1.0$ & $4.9 \pm 0.5$ & $3.2 \pm 0.2$ \\
$\begin{array}{l}\text { Groove } \\
\text { size }(\mu \mathrm{m})\end{array}$ & $60.8 \pm 15.6$ & $42.0 \pm 10.1$ & $32.1 \pm 8.1$ & $17.7 \pm 4.7$ & $5.7 \pm 2.1$ \\
\hline
\end{tabular}

the protruded particles on the obtained coating were accordingly decreased in size. Table 1 summarizes the surface roughness of the microstructured coatings. From P240 to P2000, the arithmetic average of the roughness profile $\left(R_{a}\right)$ decreased from $\sim 9.5 \mu \mathrm{m}$ to $\sim 3.2 \mu \mathrm{m}$. Moreover, the groove size, defined as the averaged distance between adjacent protrusions on the microstructured coatings, was also markedly decreased from $\sim 60.8 \mu \mathrm{m}$ (P240) to $\sim 5.7 \mu \mathrm{m}$ (P2000).

3.2. Surface Wettability. Surface wettability is closely related to the anticorrosive capability of barrier coatings. Increasing the hydrophobicity would decrease interaction between water and polymer chains and retard water diffusion, thereby enhancing the barrier properties. Epoxy coatings are very commonly used as barrier coatings in severely corrosive environments due to their high mechanical and thermal stability, high chemical resistance, and excellent adhesion to metal substrates $[1,20]$. However, they are generally considered hydrophilic as they contain abundant polar groups such as hydroxyl, amino, and carboxyl groups [2]. Significant efforts have been made to improve their hydrophobicity, most commonly via covalently cross-linking with hydrophobic siloxane or fluorinated moieties. However, these moieties are often present throughout entire coatings, causing undesirable loss of adhesion to metal substrates [21].

Surface microstructures also significantly influence the wettability. Figure 2 shows the contact angles of a $5 \mu \mathrm{L}$ water droplet on PDMS templates obtained by different sandpapers and their corresponding epoxy coatings. For PDMS, the contact angle on a flat surface is $115.3^{\circ}$, exhibiting high hydrophobicity. The rough PDMS surfaces show slight increases in the hydrophobicity. From P240 to P2000, the contact angle was increased from $121.6^{\circ}$ to $129.9^{\circ}$. For epoxy coatings, however, introducing roughness causes a dramatic increase in contact angle from $72.7^{\circ}$ (flat) to $111.7^{\circ}$ (P240). A decreased groove size results in a further increase in hydrophobicity and the epoxy coating obtained from P2000 sandpaper shows the highest contact angle of $126.7^{\circ}$. On microstructured surface, a water droplet can generally contact in either Wenzel or Cassie

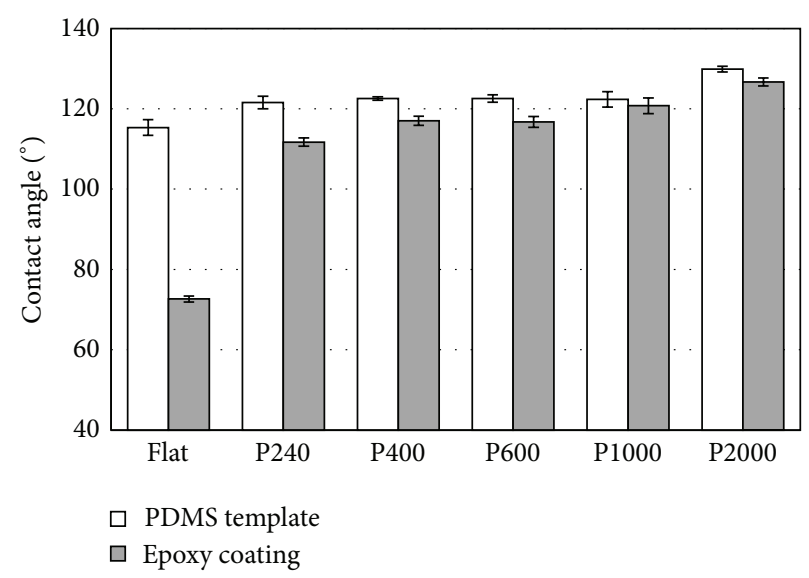

Figure 2: Water contact angles on PDMS templates and epoxy coatings.

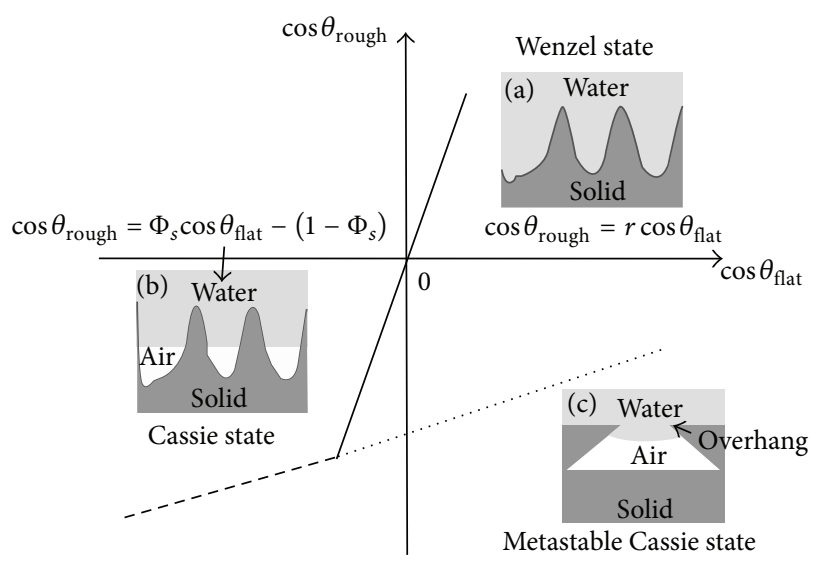

FIGURE 3: Relationships of $\cos \theta_{\text {rough }}$ with $\cos \theta_{\text {flat }}$. This figure was adapted from [23].

mode [22]. The relationship between the contact angles on flat surface $\left(\theta_{\text {flat }}\right)$ and microstructured surface $\left(\theta_{\text {rough }}\right)$ for Wenzel and Cassie modes is demonstrated in Figure 3 [23]. At Wenzel state (solid line, Figure 3(a)), water completely fills the microstructures. The contact angles of the water droplet follow the following equation:

$$
\cos \theta_{\text {rough }}=r \cos \theta_{\text {flat }},
$$

where $r$ is the roughness factor, $\theta_{\text {rough }}$ is the contact angle on rough surface, and $\theta_{\text {flat }}$ is the material's intrinsic contact angle. At Cassie state (dashed line, Figure 3(b)), water cannot 


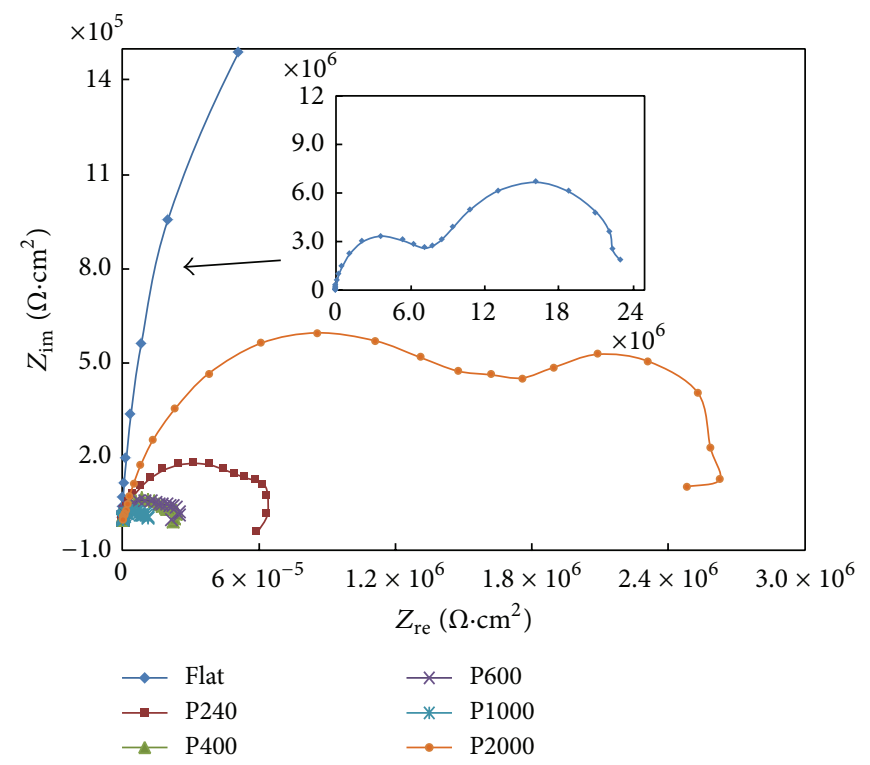

(a)

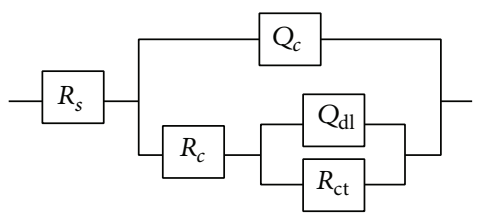

(b)

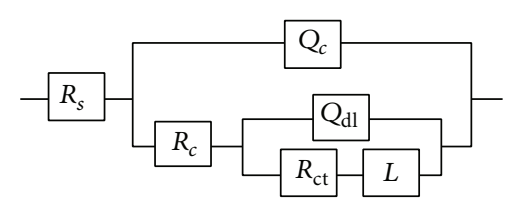

(c)

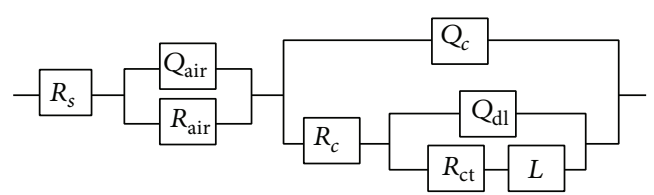

(d)

FIGURE 4: Nyquist plots (a) from EIS measurements and equivalent circuits (b-d) for flat and microstructured coatings.

fully penetrate into the microstructures and is thereby in contact with a composite surface of trapped air and protruded particles. The contact angles of water droplets at Cassie state follow the following equation:

$$
\cos \theta_{\text {rough }}=\Phi_{s} \cos \theta_{\text {flat }}-\left(1-\Phi_{s}\right),
$$

where $\Phi_{s}$ is the area fraction of the solid/water interface. Clearly, the classic Cassie contacts only occur on intrinsically hydrophobic surfaces (the 3rd quadrant in Figure 3). It is thermodynamically unfavored for an intrinsically hydrophilic material to show hydrophobic behaviors (the 4th quadrant in Figure 3) when roughened. This is shown as the dotted line in Figure 3 and is referred to as metastable Cassie state. At this state, overhanging microstructures (Figure 3(c)) are needed so that water cannot fully penetrate into the grooves due to an energy barrier provided by the capillary force. In Figures 1(i) and 1(l), the protruded $\mathrm{SiC}$ microparticles on sandpapers form such overhanging microstructures and are responsible for the increase in hydrophobicity to $\theta_{\text {rough }}>90^{\circ}$ on the microstructured epoxy coatings. As the groove size decreases, it is more difficult for water to enter the microstructures and penetrate the trapped air, resulting in higher contact angles.

3.3. EIS Analysis. The anticorrosive performance of the microstructured epoxy coatings was evaluated by EIS, which measures the dielectric properties of the coatings over a range of frequencies. Figure 4(a) shows the Nyquist plots from EIS measurements. Two capacitive loops were observed for all coatings, suggesting that water has penetrated through the coating and has reached the metal substrate [24]. As a result, electrochemical reaction takes place at the coating/substrate interface. The equivalent circuit for flat coating is given in Figure 4(b), where $R_{s}$ is the resistance of $\mathrm{NaCl}$ solution. $Q_{c}$ and $R_{c}$ are the constant phase element (CPE) and the resistance of the coating, respectively. $Q_{\mathrm{dl}}$ is CPE of the electrical double layer and $R_{\mathrm{ct}}$ is the charge transfer resistance. Despite the increasing hydrophobicity, the anticorrosive performance of the coating was reduced for the microstructured coatings, as shown by the smaller capacitive loops. This can be explained by the increasing amount of defects formed by protrusions on PDMS templates during the imprinting process. As the protrusions on the PDMS templates become finer, more defects can be created within a given area of the corresponding coating. Therefore, the diameter of the capacitive loop is decreased from P240 to P1000. Interestingly, the capacitive loop becomes significantly larger for P2000 coating. This was possibly due to the fact that the grooves on P2000 were too small for water to fully penetrate through. The trapped air was not yet replaced by $\mathrm{NaCl}$ solution, adding to the total barrier property [18]. Besides capacitive loops, the microstructured coatings also show inductive loops at low frequency region, which can be attributed to the adsorbed 


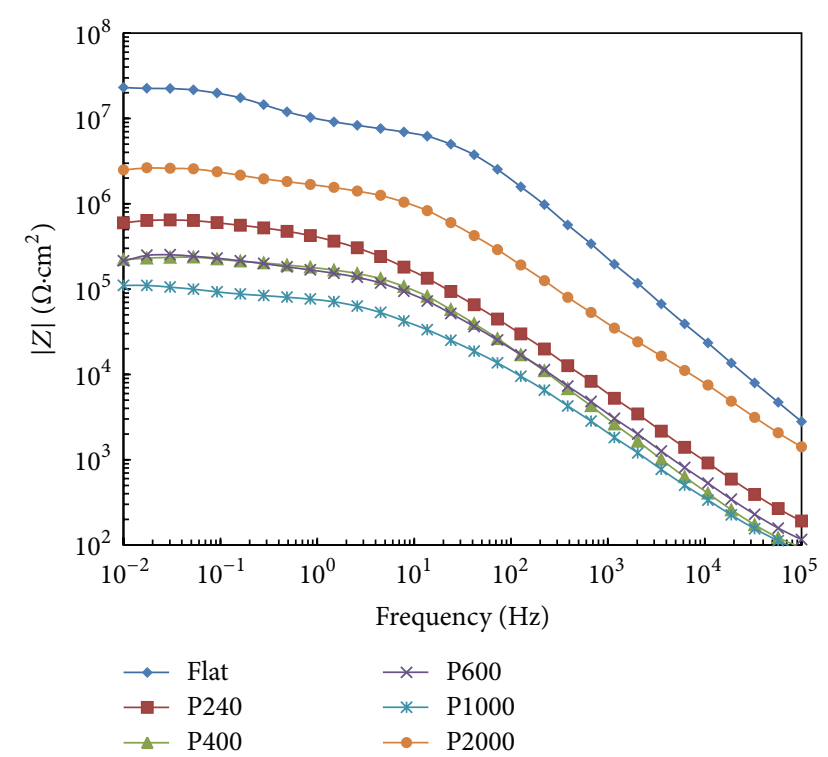

Figure 5: Bode plots from EIS measurements for flat and microstructured coatings.

corrosion product in the coating defects [25]. The equivalent circuits for P240-P1000 and P2000 are shown in Figure 4(c) and Figure $4(\mathrm{~d})$, respectively. $L$ is inductance of the corrosion product. For P2000, CPE $\left(Q_{\text {air }}\right)$ and resistance $\left(R_{\text {air }}\right)$ of the trapped air were added for a better fit to the measured data. In the case of Bode plots (Figure 5), the $|Z|$ value at low frequency is often used as a measure for coating's barrier property $[2,4]$. An ideal coating exhibits pure capacitive behavior and thus a very high $|Z|$ value. Similar to the Nyquist plots, $|Z|$ values were decreased from flat coating to P1000, followed by an increase for the P2000 coating.

Enhancing the hydrophobicity of flat coatings is often achieved by incorporating hydrophobic components which lower the interaction with water and improve the barrier property. In contrast, the increase in water contact angle of rough coating is often attributed to the air trapped with the microstructures and does not always produce a concurrent improvement in anticorrosive performance $[12,26]$. For example, it has been recently shown that the trapped air which can withstand the pressure of a water droplet might not be stable in immersed condition [12]. Once penetrated by water, the coatings exhibited much lower protection over the metal substrates.

\section{Conclusions}

In this study, solvent-free epoxy coatings with sandpaper-like microstructured surfaces were prepared via a soft lithography method. Sandpapers with different grit numbers were used to control the groove size on the microstructured coatings. Compared to flat epoxy coating, the water contact angle was significantly higher for the microstructured coating and was found to further increase with decreasing groove size. However, the enhanced hydrophobicity of microstructured coatings did not produce concurrent increases in barrier properties from EIS analysis, possibly due to the more prevalent defects formed in the imprinting process. As the grit size of sandpaper was further decreased (P2000), the grooves on the microstructured coating became much smaller. It was more difficult for $\mathrm{NaCl}$ solution to fully penetrate the trapped air, resulting in a better barrier property.

\section{Conflict of Interests}

The authors declare that there is no conflict of interests regarding the publication of this paper.

\section{Acknowledgments}

This work is supported by the National Natural Science Foundation of China (no. 51401018), the National Basic Research Program of China (973 Program Project, no. 2014CB643300), and the Fundamental Research Funds for the Central Universities (no. FRF-TP-14-044A1).

\section{References}

[1] P. A. Sørensen, S. Kiil, K. Dam-Johansen, and C. E. Weinell, "Anticorrosive coatings: a review," Journal of Coatings Technology Research, vol. 6, no. 2, pp. 135-176, 2009.

[2] M. Shon and H. Kwon, "Comparison of surface modification with amino terminated polydimethylsiloxane and amino branched polydimethylsiloxane on the corrosion protection of epoxy coating," Corrosion Science, vol. 51, no. 3, pp. 650-657, 2009.

[3] R. Posner, M. Santa, and G. Grundmeier, "Wet- and corrosive de-adhesion processes of water-borne epoxy film coated steel. I. interface potentials and characteristics of ion transport processes," Journal of the Electrochemical Society, vol. 158, no. 3, pp. C29-C35, 2011.

[4] Q. Zhou and Y. Wang, "Comparisons of clear coating degradation in $\mathrm{NaCl}$ solution and pure water," Progress in Organic Coatings, vol. 76, no. 11, pp. 1674-1682, 2013.

[5] G. Verma, S. K. Dhoke, and A. S. Khanna, "Polyester basedsiloxane modified waterborne anticorrosive hydrophobic coating on copper," Surface and Coatings Technology, vol. 212, pp. 101-108, 2012.

[6] C. Zhou, X. Lu, Z. Xin, J. Liu, and Y. Zhang, "Hydrophobic benzoxazine-cured epoxy coatings for corrosion protection," Progress in Organic Coatings, vol. 76, no. 9, pp. 1178-1183, 2013.

[7] M. F. Montemor, "Functional and smart coatings for corrosion protection: a review of recent advances," Surface and Coatings Technology, vol. 258, pp. 17-37, 2014.

[8] X.-M. Li, D. Reinhoudt, and M. Crego-Calama, "What do we need for a superhydrophobic surface? A review on the recent progress in the preparation of superhydrophobic surfaces," Chemical Society Reviews, vol. 36, no. 8, pp. 1350-1368, 2007.

[9] V. C. Malshe and N. S. Sangaj, "Fluorinated acrylic copolymers: part I: study of clear coatings," Progress in Organic Coatings, vol. 53 , no. 3, pp. 207-211, 2005.

[10] X. Cui, Y. Gao, S. Zhong, Z. Zheng, Y. Cheng, and H. Wang, "Synthesis and surface properties of Semi-interpenetrating fluorine-containing polyacrylate and epoxy resin networks," Journal of Polymer Research, vol. 19, no. 3, article 9832, 2012. 
[11] T. Ishizaki, Y. Masuda, and M. Sakamoto, "Corrosion resistance and durability of superhydrophobic surface formed on magnesium alloy coated with nanostructured cerium oxide film and fluoroalkylsilane molecules in corrosive $\mathrm{NaCl}$ aqueous solution," Langmuir, vol. 27, no. 8, pp. 4780-4788, 2011.

[12] D. Yu and J. Tian, "Superhydrophobicity: Is it really better than hydrophobicity on anti-corrosion?" Colloids and Surfaces A: Physicochemical and Engineering Aspects, vol. 445, pp. 75-78, 2014.

[13] P. Wang, D. Zhang, and Z. Lu, "Advantage of super-hydrophobic surface as a barrier against atmospheric corrosion induced by salt deliquescence," Corrosion Science, vol. 90, pp. 23-32, 2015.

[14] T. Liu, Y. Yin, S. Chen, X. Chang, and S. Cheng, "Superhydrophobic surfaces improve corrosion resistance of copper in seawater," Electrochimica Acta, vol. 52, no. 11, pp. 3709-3713, 2007.

[15] J. Ou, W. Hu, M. Xue, F. Wang, and W. Li, "Superhydrophobic surfaces on light alloy substrates fabricated by a versatile process and their corrosion protection," ACS Applied Materials \& Interfaces, vol. 5, no. 8, pp. 3101-3107, 2013.

[16] L. Li, Y. Zhang, J. Lei et al., "A facile approach to fabricate superhydrophobic Zn surface and its effect on corrosion resistance," Corrosion Science, vol. 85, pp. 174-182, 2014.

[17] D. Qin, Y. Xia, and G. M. Whitesides, "Soft lithography for micro- and nanoscale patterning," Nature Protocols, vol. 5, no. 3, pp. 491-502, 2010.

[18] K.-C. Chang, M.-H. Hsu, H.-I. Lu et al., "Room-temperature cured hydrophobic epoxy/graphene composites as corrosion inhibitor for cold-rolled steel," Carbon, vol. 66, pp. 144-153, 2014.

[19] I. D. Johnston, D. K. McCluskey, C. K. L. Tan, and M. C. Tracey, "Mechanical characterization of bulk Sylgard 184 for microfluidics and microengineering," Journal of Micromechanics and Microengineering, vol. 24, no. 3, Article ID 035017, 2014.

[20] Y. Hao, F. Liu, H. Shi, E. Han, and Z. Wang, “The influence of ultra-fine glass fibers on the mechanical and anticorrosion properties of epoxy coatings," Progress in Organic Coatings, vol. 71, no. 2, pp. 188-197, 2011.

[21] G. Z. Li, L. Wang, H. Toghiani, T. L. Daulton, K. Koyama, and C. U. Pittman Jr., "Viscoelastic and mechanical properties of epoxy/multifunctional polyhedral oligomeric silsesquioxane nanocomposites and epoxy/ladderlike polyphenylsilsesquioxane blends," Macromolecules, vol. 34, no. 25, pp. 8686-8693, 2001.

[22] K. Liu, Y. Tian, and L. Jiang, "Bio-inspired superoleophobic and smart materials: design, fabrication, and application," Progress in Materials Science, vol. 58, no. 4, pp. 503-564, 2012.

[23] L. Cao, H.-H. Hu, and D. Gao, "Design and fabrication of micro-textures for inducing a superhydrophobic behavior on hydrophilic materials," Langmuir, vol. 23, no. 8, pp. 4310-4314, 2007.

[24] B. Liu, Y. Li, H. Lin, and C.-N. Cao, "Effect of PVC on the diffusion behaviour of water through alkyd coatings," Corrosion Science, vol. 44, no. 12, pp. 2657-2664, 2002.

[25] P. C. Okafor, X. Liu, and Y. G. Zheng, "Corrosion inhibition of mild steel by ethylamino imidazoline derivative in $\mathrm{CO}_{2}$ saturated solution," Corrosion Science, vol. 51, no. 4, pp. 761-768, 2009.

[26] R. Qiu, D. Zhang, and P. Wang, "Superhydrophobic-carbon fibre growth on a zinc surface for corrosion inhibition," Corrosion Science, vol. 66, pp. 350-359, 2013. 

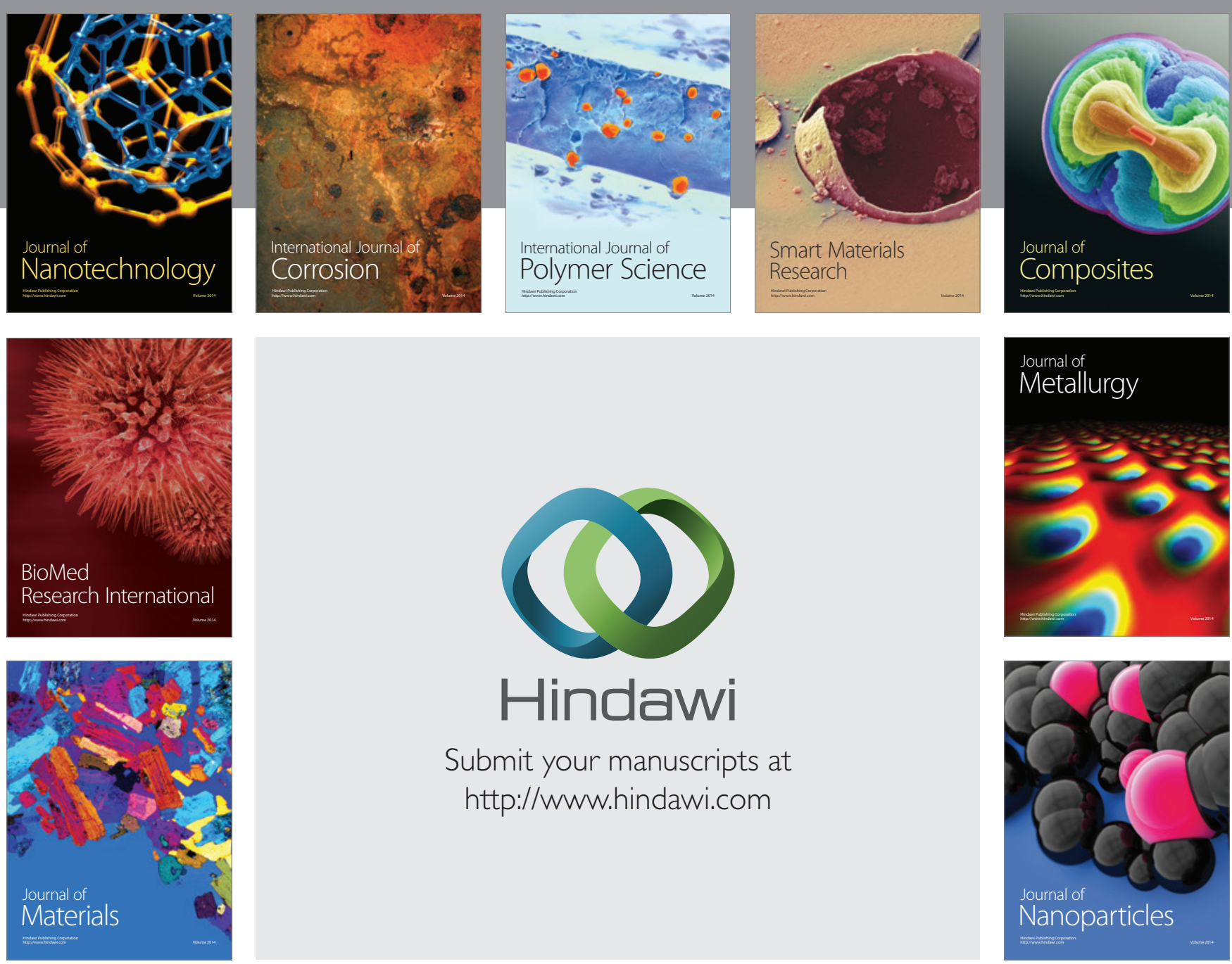

Submit your manuscripts at http://www.hindawi.com
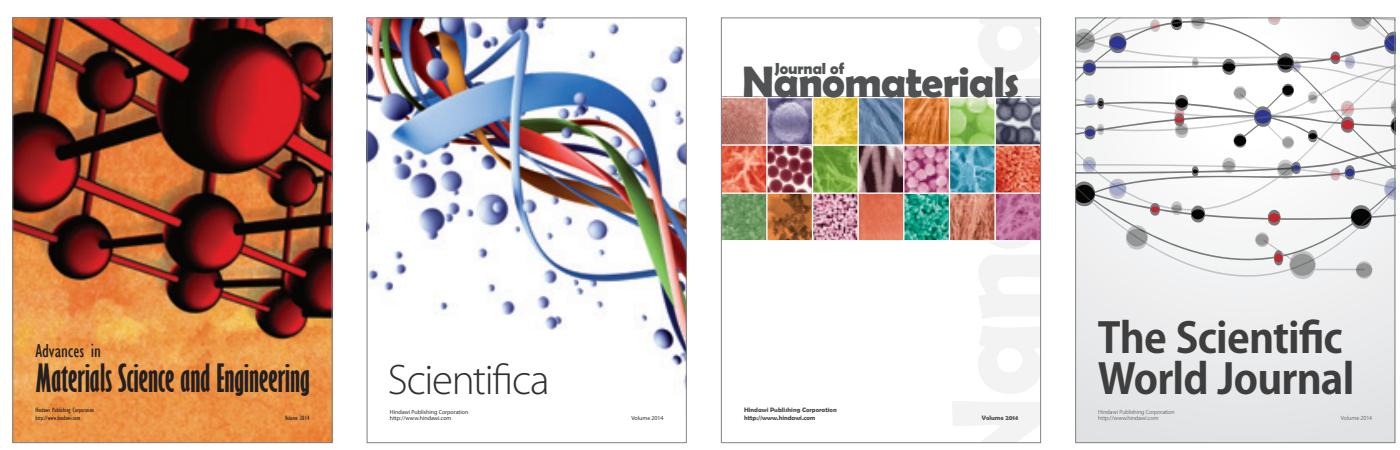

\section{The Scientific World Journal}
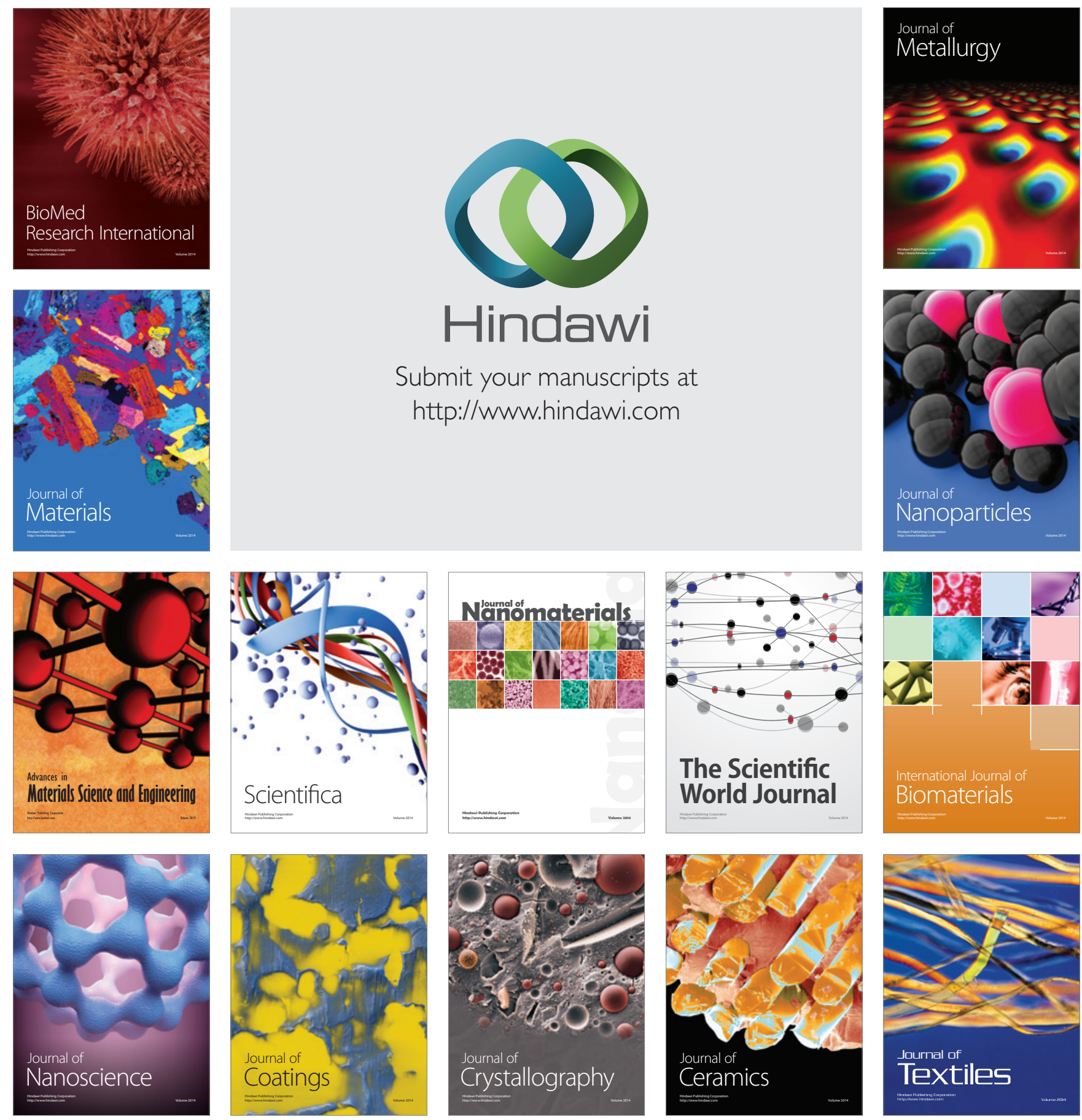